\title{
PREPARAÇÃO PROFISSIONAL EM EDUCAÇÃO FÍSICA E ESPORTE: PASSADO, PRESENTE E DESAFIOS PARA O FUTURO
}

\author{
Edison de Jesus MANOEL \\ Go TANI**
}

\section{INTRODUÇÃO}

Em meados de 1985, um de nós encontrou, no Centro Residencial da Universidade de São Paulo, um velho amigo de infância que àquela altura era aluno da Faculdade de Filosofia, Ciências e Letras da mesma Universidade. Com satisfação lhe disse que havia terminado o curso de graduação em Educação Física e agora estava no segundo ano do programa de mestrado na Escola de Educação Física desta Universidade (EEFEUSP). Igualmente contente, esse amigo disparou: "...que bom assim você pode continuar mantendo a forma física ....." Esse ponto de vista sintetiza a concepção que predominou e ainda predomina quanto à natureza da preparação profissional na área em nosso país. Com grande facilidade se confunde o profissional de Educação Física com aquele individuo altamente habilidoso, musculoso e em plena forma física. Durante décadas, os cursos de preparação profissional pouco fizeram para modificar essa imagem, de fato, podemos dizer que em sua estrutura eles a fortaleceram e a legitimaram.

Ao longo de 30 anos, a EEFEUSP tem lutado contra essa concepção por meio de ações concretas, fielmente refletidas nas modificações e, no nosso entender, inovações promovidas nos cursos de graduação pelos quais é responsável. $\mathrm{O}$ presente trabalho tem por objetivo refletir sobre essas modificações, discutindo as bases que as suportaram. Além disso, pretende levantar os desafios que se apresentam para a consolidação dos cursos de preparação profissional atualmente oferecidos por essa Unidade.

\section{AS CARACTERISTICAS DA EDUCAÇÃO FÍSICA E A PREPARAÇÃO PROFISSIONAL NA EEFEUSP}

A nossa abordagem do problema parte do entendimento que a preparação profissional não se restringe à implementação de uma determinada grade curricular. Ela implica uma filosofia acerca dessa preparação e depende, antes de mais nada, de uma clara definição do perfil profissional da pessoa que se quer formar. Esse perfil, por sua vez, está intimamente relacionado às necessidades sociais e às características de mercado de trabalho que são muito dinâmicas. A preparação profissional depende também do nível de maturidade acadêmica da área, ou seja, dos conhecimentos disponiveis para serem transmitidos a futuros profissionais, além da qualidade do corpo docente que tem a responsabilidade de difundi-los.

A problemática da preparação profissional em Educação Física tem sido abordada de várias formas no Brasil e no mundo. Um aspecto que distingue a nossa abordagem do problema das demais empreendidas em território nacional foi a preocupação em não dissociar 0 debate sobre essa preparação com a discussão da caracterização acadêmica da área.

Chefe do Departamento de Pedagogia do Movimento do Corpo Humano da Escola de Educação Física e Esporte da Universidade de São Paulo.

"* Coordenador do Laboratório de Comportamento Motor da Escola de Educação Física e Esporte da Universidade de São Paulo. 
A proposição da Educação Física como uma área de conhecimento é recente e não menos controversa. Na América do Norte e em alguns paises europeus, essa proposição ganhou força nos anos 60 (cf. Henry, 1964; Rarick, 1967; Whiting, 1975). Foge ao escopo do presente trabalho discutir esse processo que já foi abordado em outras publicações (por exemplo, Manoel, 1986, 1996; Tani, 1988, 1996a, 1998). O fato é que enquanto a atuação profissional em Educação Física foi vista de forma dissociada de seu caráter acadêmico, os cursos de preparação profissional foram norteados por disciplinas de orientação a atividades práticas como esportes, jogos e dança. Como já dissemos anteriormente, isso reforçou a figura do profissional como executante e fez com que, como categoria profissional, o "status" ocupacional atribuído aos indivíduos formados em Educação Física fosse o de um artesão (Morford, 1972).

A principal diferença entre ocupação e profissão, segundo Lawson (1984), é que numa ocupação as pessoas atuam com base em métodos transmitidos de geração a geração, dependentes da tradição calcada em tentativas e erros dos indivíduos envolvidos na prática. Numa profissão, as pessoas estão comprometidas com uma carreira, sendo a maneira de executar o trabalho baseada no conhecimento sobre a essência do serviço que oferecem e sobre a pessoa a quem prestam esse serviço. Além disso, como as transformações sociais geram pressões para a modificação do conhecimento, o profissional deve ser capaz de adaptar ou alterar a sua maneira de trabalhar.

Em que pese as controvérsias sobre a relevância da caracterização como uma disciplina acadêmica (cf. Newell, 1990), não há como negar que a estruturação e a produção de conhecimentos sobre a atividade motora humana propiciou um corpo de conhecimentos específico capaz de dar identidade e legitimidade acadêmicas à área. Esse processo tem sido o mais forte elemento para modificar o "status" da preparação profissional, de um curso mais condizente com uma preparação técnica profissionalizante de nível secundário ou médio, para um curso academicamente orientado, de nivel superior.

Nesse sentido, vemos que a orientação do curso de graduação da EEFEUSP esteve diretamente relacionada com 0 desenvolvimento da pós-graduação em Educação Física na mesma Unidade. À medida que a pósgraduação foi se estruturando e se modificando, 0 curso de graduação também passou por transformações. Esse processo pode ser resumido em dois marcos. Primeiro, tivemos o aumento no número mínimo de anos para a obtenção do grau, de três para quatro anos. Segundo, tivemos a diferenciação da preparação profissional, que na prática significou a criação de três novos cursos: Bacharelado e Licenciatura em Educação Física e Bacharelado em Esporte. Assim, é possivel identificar duas fases na estruturação do curso de graduação em Educação Física a partir do momento em que a Unidade foi incorporada à Universidade de São Paulo. A seguir abordaremos cada uma dessas fases.

\section{FASE I: INÍCIO DA ORIENTAÇÃO ACADÊMICA}

A Educação Física tem uma tradição relativamente longa como um curso de preparação profissional. Inicialmente, o seu objetivo principal era formar professores para atuar no ensino formal, daí a sua caracterização como um curso de licenciatura. De fato, o magistério absorvia praticamente todos os egressos, mesmo porque as oportunidades de trabalho fora da Educação Física escolar eram muito reduzidas. Com isso, o curso de preparação profissional conseguia manter uma certa coerência interna, pois formava apenas um tipo de profissional.

Nesse contexto, as escolas de Educação Física ofereciam, basicamente, uma estrutura curricular composta de três grandes grupos de disciplinas: a) disciplinas academicamente orientadas, que ofereciam os conhecimentos teóricos provenientes das chamadas ciências-mãe; b) disciplinas orientadas às atividades, que eram centradas em jogo, esporte, dança, ginástica e recreação e c) disciplinas de orientação pedagógica, que abordavam aspectos relacionados com o ensino no sentido amplo (Tani, 1996).

Em razão da concepção eminentemente prática da profissão e da ausência de um corpo de conhecimentos devidamente estruturado, a ênfase recaía invariavelmente nas disciplinas de orientação para as atividades. $O$ lema era "aprender a executar para poder ensinar" e, portanto, ofereciam-se muitas disciplinas práticas, particularmente vinculadas às modalidades esportivas tradicionais, nas quais os graduandos experimentavam uma grande variedade de movimentos com o objetivo de adquirir habilidades 
motoras específicas e de melhorar as então chamadas valências físicas. $O$ professor deveria ser um modelo para seus alunos, não apenas na execução de movimentos para demonstrar, como também no que se refere a hábitos de saúde, higiene e asseio corporal.

O grupo de disciplinas academicamente orientadas trabalhava com conhecimentos básicos das ciências-mãe, com grande ênfase na área biológica, como a Anatomia, a Fisiologia e a Cinesiologia (atualmente Biomecânica). Pouco se trabalhava com as áreas comportamentais e sócio-culturais, como a Psicologia, a Sociologia e a Antropologia, pois prevalecia uma concepção essencialmente biológica do ser humano e da atividade motora.

O grupo de disciplinas de orientação pedagógica centrava-se na discussão de aspectos metodológicos de ensino com base nas teorias genéricas da Pedagogia, visto que conhecimentos elaborados sobre a metodologia de ensino específica da Educação Física praticamente inexistiam.

Essa estrutura de preparação profissional prevaleceu por longo tempo, apesar de várias limitações a ela inerentes como, por exemplo, o caráter muito genérico das disciplinas de orientação pedagógica, a falta de integração destas com as disciplinas orientadas às atividades, a simples reprodução de técnicas de movimento nas disciplinas orientadas às atividades $\mathrm{e}$ a superficialidade dos conhecimentos teóricos desenvolvidos (Tani, 1996). O curso de preparação profissional que a EEFEUSP oferecia, quando da sua incorporação pela USP, tinha essas características.

Entretanto, uma mudança importante começava a tomar vulto no final da década de 70 . A busca para ampliar a fundamentação teórica do futuro profissional levou ao reconhecimento da necessidade de incluir novas disciplinas não só de natureza biológica, mas também de natureza psicológica e social. Assim, entre 1979 e 1986, foram incluídas na grade curricular várias disciplinas como Crescimento e Desenvolvimento, Aprendizagem Motora, Biomecânica, Recreação e Lazer, entre outras. Além disso, houve uma preocupação em criar disciplinas de orientação pedagógica que estabelecessem uma vinculação mais apropriada entre a atividade motora e as características da população a que se destinava. Dessa forma, surgiram a Educação Física na Adolescência, a Educação Física na Idade Adulta e a Educação Física Adaptada. Essas modificações não ocorreram todas ao mesmo tempo, pois o oferecimento de tais disciplinas estavam vinculadas aos recursos humanos que estavam sendo formados na época. De qualquer maneira, antecipando as modificações que viriam, o curso de graduação passou de três anos para quatro anos a partir de 1979. Na época, esse era um dos únicos cursos, talvez o único, a exigir oito semestres letivos para a obtenção do grau de Licenciado em Educação Física.

Claramente esse foi $o$ período em que o pêndulo começou a tender para as disciplinas de orientação acadêmica. Ao mesmo tempo, iniciou-se um debate sobre a natureza das disciplinas de orientação à atividade prática em que pese a grande resistência em modificar a condução dessas disciplinas devido à forte influência histórica que elas carregavam.

A ampliação dos conhecimentos acadêmicos sobre a população a quem se destinam os nossos serviços, mais as mudanças no mercado de trabalho nos anos $80^{1}$, levaram a uma gradual tomada de consciência de que as possibilidades de atuação profissional extrapolavam em muito as ocupações tradicionais na área como professor de educação física no ensino formal ou como técnico esportivo. De fato, dados levantados nesse período mostravam o desinteresse dos egressos do curso para a atuação na escola, principalmente (Mariz de Oliveira, 1988). Iniciava-se, assim, a transição para a Fase II.

\section{FASE II: DIFERENCIAÇÃO DE ÁREAS E CRIAÇÃO DO BACHARELADO}

A crescente infusão de conhecimentos acadêmicos sobre as várias dimensões da atividade motora humana levou a um reconhecimento de que Educação Física e Esporte mereciam um tratamento diferenciado no que diz respeito à preparação profissional. A atividade motora ganhou e continua a ganhar grande evidência por se constituir um elemento de crucial importância para que se alcance a saúde (Bouchard, Shephard \& Stephens, 1993) ou qualidade de vida (Burt, 1998). O esporte, por outro lado, vem sendo reconhecido desde os anos 60, como um fenômeno sócio-cultural de grande impacto. A onda crescente de profissionalização, iniciada de forma abrangente em meados dos anos 80 , catapultou o interesse pelo esporte como um ramo de atividade profissional extremamente 
atraente. A atuação não se restringe à orientação técnica, tática e física de atletas e equipes, mas passa a incluir também a organização e promoção de eventos e programas esportivos.

A EEFEUSP inovou ao demonstrar a necessidade de se diferenciar a preparação profissional, com individuos aptos para atuar com a atividade motora da população em geral e para atuar com o esporte para gnupos selecionados. Mas havia ainda outro ponto que mereceu atenção e que dizia respeito à ambigüidade da formação terminal denominada Licenciado em Educação Física. Em geral, no ensino superior, o aluno obtém uma formação na qual ele se aprofunda nos conhecimentos de uma área ou disciplina acadêmica. Por exemplo, o estudante de Química adquire conhecimentos sobre a área de conhecimento Química. Ao se formar, passa a ter posse de um corpo de conhecimentos solidamente constituído com base na experimentação científica, ou seja, ele se torna um bacharel em Química. Caso ele queira difundir esses conhecimentos no âmbito escolar, ele deverá obter uma licença para tanto e isso implica freqüentar disciplinas especialmente desenvolvidas pela Faculdade de Educação. Esse é o sistema comum na USP. Entretanto, o curso de graduação em Educação Física apresentava a ambigüidade de formar licenciados que na maioria das vezes jamais atuariam na escola. Ao mesmo tempo, o corpo de conhecimentos da Educação Física era mal definido.

A necessidade de transformação do curso de Licenciatura em curso de Bacharelado começou a ser discutida entre 1983 e 1984 . Como era de se esperar, a idéia foi recebida com grande resistência, pois não se tratava apenas de uma mudança de nomenclatura, mas de uma filosofia acerca da preparação profissional. Não seria exagero dizer que àquela altura a proposta de criação do curso de bacharelado implicava uma ruptura com uma tradição de 50 anos. Na EEFE, a mudança envolveu não só a preparação profissional, mas a reestruturação departamental, pós-graduação, entre outros.

No embate que se travou nos anos seguintes acabou prevalecendo a idéia inovadora que foi grandemente influenciada pelo projeto de lei que resultou na resolução no. 03/87 do Ministério da Educação e Desportos, criando o curso de Bacharelado com duração mínima de quatro anos. Assim, duas inovações que o curso de graduação da EEFEUSP buscou implementar duração de oito semestres e criação do Bacharelado
- acabaram por se tornar obrigatórias em todo território nacional. Num aspecto, a resolução no.03/87 foi infeliz: ela deu continuidade à ambigüidade, ao permitir que os cursos de Bacharelado e Licenciatura fossem equivalentes.

Na EEFEUSP, a decisão oficial para a criação do Bacharelado só ocorreu em 1989. A proposta trazia em seu bojo três novos cursos: Bacharelado em Esporte, Bacharelado e Licenciatura em Educação Física. Nesses cursos, predominavam as disciplinas de orientação acadêmica com uma importante diferença em relação à Fase I: além das disciplinas básicas oriundas das ciências-mãe, foram introduzidas disciplinas originadas numa perspectiva transdisciplinar com conhecimentos sobre a Biodinâmica do Movimento Humano, o Comportamento Motor Humano e os Estudos Sócio-culturais do Movimento Humano. Além delas, encontramos uma outra fonte de inovação nas disciplinas de orientação pedagógica que passaram a enfocar 0 desenvolvimento de procedimentos didático-pedagógicos vinculados às características desenvolvimentistas da população. As disciplinas com orientação para atividades práticas deixaram de figurar da grade (no caso do Bacharelado e da Licenciatura em Educação Física) ou tiveram sua participação reduzida na formação final do aluno (no caso do Bacharelado em Esporte). Ou seja, as mudanças introduzidas a partir de 1992, ano em que os novos cursos passaram a funcionar, estavam alinhadas com uma concepção mais apropriada do que é ser um profissional (cf. Lawson, 1984).

O novo curso de Licenciatura passou a ser facultativo para todos aqueles que cursavam o Bacharelado em Educação Física. Dessa forma, buscou-se caracterizar que o indivíduo que escolhe como área de atuação a escola está de posse de um corpo de conhecimentos sobre a atividade motora humana e sobre os processos de sua promoção no plano individual, em grupo e institucional. A Licenciatura também inovou na medida em que uma série de disciplinas foi criada enfocando a Educação Física nos diferentes segmentos da escola. Dessa forma, o mínimo estabelecido pela legislação para a obtenção da licença (referente aos créditos das disciplinas tradicionalmente oferecidas pela Faculdade de Educação) foi extrapolado em muito pelo novo curso. Isso faz da Licenciatura na EEFEUSP um curso único hoje no Brasil.

Como dissemos no início desse trabalho, a grande atenção que a atividade motora $e$ o esporte têm recebido por parte da comunidade 
nos faz ver que os bacharéis em Esporte e em Educação Física têm um campo aberto e profícuo de atuação. $O$ volume e a qualidade dos conhecimentos básicos sobre 0 indivíduo em movimento pode propiciar, inclusive, uma maior capacidade de adaptação e renovação dos serviços oferecidos à população. Essa capacidade é crucial para qualquer profissional, em qualquer área, atualmente. Em linhas gerais, espera-se que o Bacharel em Educação Física tenha condições de planejar, implementar e avaliar programas de Educação Física para a população em geral e para indivíduos portadores de deficiência em particular, no contexto não-escolar. Já o Licenciado em Educação Física deverá estar preparado para planejar, implementar e avaliar programas de Educação Física nos vários ciclos da escolarização: educação infantil, ensino fundamental e médio. $O$ Bacharel em Esporte, por sua vez, deverá desenvolver funções de orientação e preparação física, técnica e tática para atletas ou equipes esportivas, além de atuar na organização e promoção de eventos esportivos.

\section{DESAFIOS PARA A PREPARAÇÃO PROFISSIONAL}

A existência de um curso de Bacharelado pressupõe a existência de um corpo de conhecimentos produzido e sistematizado pela área. Pode-se dizer que, no momento da proposição dos cursos de Bacharelado e Licenciatura na EEFEUSP, o corpo de conhecimentos da área ainda era incipiente. $\mathrm{Na}$ época, a própria infraestrutura para a produção desses conhecimentos na Unidade começava a ser estruturada ${ }^{2}$ Ou seja, a proposição dos novos cursos envolveu um pensamento teleológico no qual o estabelecimento de uma meta (do futuro, portanto) - sistematização e difusão do corpo de conhecimentos da área deveria exercer pressões para a modificação do comportamento dos elementos do sistema (corpo docente) no presente. Ou seja, o pleno desenvolvimento do bacharelado e da licenciatura demanda um amplo envolvimento do corpo docente na produção sistemática de conhecimentos.

Coincidentemente, uma estratégia similar foi adotada na proposição e conseqüente criação do curso de Mestrado em Educação Física em 1977. Naquela época, a pesquisa era ainda muito incipiente na Educação Física, mas a criação de um curso de pós-graduação também estabelecera uma meta futura que funcionou como causa para modificar comportamentos do presente. A efetividade dessas estratégias pode ser questionada, mas para alguns a necessidade de sua utilização era inevitável (Tani, 1997). Evidentemente que o maior desafio que se coloca para os cursos de graduação da EEFEUSP é o de ter disponível um corpo de conhecimentos necessário para dar sustentação a uma preparação profissional sólida. As avaliações iniciais do curso de Bacharelado em Educação Física mostram que a resposta do corpo docente ainda está aquém do esperado (Manoel, 1996b; Tani, 1997).

Portanto, acreditamos que os principais desafios para os cursos de graduação da EEFEUSP estão em direta relação com os desafios para a área de pesquisa. Sem a produção de conhecimentos não há como difundi-los. Em outros trabalhos já destacamos a necessidade premente de que se estabeleça uma estrutura integrada de produção de conhecimentos básicos, aplicados e tecnológicos (Manoel, 1996a; no prelo; Tani, 1992, 1995, 1996b, 1998, neste número). Esse corpo de conhecimentos seria então sistematizado e difundido de forma mais apropriada ao aluno de graduação. A prova de que essa cadeia de produção de conhecimentos ainda é ineficaz em nossa área, materializa-se nas dificuldades de estruturação e implementação das chamadas disciplinas de síntese no Bacharelado em Educação Física (por exemplo, Educação Física na Idade Adulta, Educação Física na Adolescência, etc.) e nas disciplinas orientadas à atividade esportiva no Bacharelado em Esporte (Atletismo, Futebol, Basquetebol, etc). A chamada dicotomia teoria-prática, cujo fantasma rondou as fases I e II do cursos de graduação, poderia ser suplantada de forma consistente, sistemática e abrangente com a formação de um corpo de conhecimentos onde a compreensão dos fenômenos naturais e artificiais fosse articulada (cf. Manoel, no prelo).

A atividade motora humana encerra uma complexidade cuja compreensão desafia as fronteiras entre disciplinas tradicionais como a Física, a Biologia, a Psicologia ou a Sociologia. Os cursos de Bacharelado em Educação Física e Esporte e a Licenciatura em Educação Física refletem, em sua grade curricular, essa busca de integração e unidade na ciência. O estudante é levado a tomar contato com áreas e conhecimentos que vão do macro ao micro, do social ao físico, do psicológico ao biológico. Essa é uma característica ainda pouco presente nos cursos de graduação em geral. Evidentemente que há várias dificuldades a 
serem suplantadas. A primeira extrapola o âmbito da área e toca num problema fundamental no plano das meta-teorias da ciência: Como integrar conhecimentos produzidos em diferentes níveis de análise? A segunda refere-se ao grau de exigência no domínio de conhecimentos de áreas tradicionais às quais o docente nem sempre teve acesso direto (via formação de nível médio e superior). A terceira dificuldade retorna ao problema de integração de conhecimentos, mas voltada para fins de orientar a prática profissional. $O$ estudante necessita aprender como conhecimentos tão diversos podem ajudá-lo a estruturar a intervenção (avaliação, planejamento, programação, implementação) ou a emitir pareceres acerca de uma dada situação-problema. Os elos de ligação entre os conhecimentos com a prática dependem não só de disciplinas que propiciem subsídios para essa aproximação mas também da orientação dada pelo corpo docente.

Muito se tem falado sobre a flexibilização dos currículos da graduação nas instituições de ensino superior nacionais, em geral, e na USP, em particular. Ao aluno deve ser dada a liberdade de escolha para montar o currículo e para encerrar a sua formação quando lhe parecer mais adequado. As razões são várias: otimizar o tempo do aluno na universidade evitando ou diminuindo a evasão, levar o aluno a ter contato com a prática mais cedo no curso de preparação profissional e dar oportunidade para que o aluno decida sobre o grau de profundidade dos conhecimentos que ele deseja assimilar. Em que pese a importância de alguns desses aspectos, vemos aqui uma abordagem orientada para administrar melhor os recursos da universidade, que corre o risco de se tornar um fim enquanto deveria ser meio. É preciso cuidar para que a filosofia que norteia a preparação profissional não fique à mercê de procedimentos que nem sempre consideram a qualidade do futuro profissional. A corrente de pensamento subjacente a esse procedimento fala muito da liberdade que 0 aluno deve ter sem se perguntar se ele tem liberdade para usufruir de tal liberdade. A distinção entre a liberdade de algo e a liberdade para realizar algo nos parece crucial em relação a essa discussão. Não se pode esquecer que o exercício da autonomia deve ser praticado desde cedo e de forma adequada a cada etapa da escolarização (Educação Infantil, Ensinos Fundamental e Médio). A ânsia em corrigir os desvios que se acumulam ao longo de toda escolarização é algo que freqüentemente provoca fervorosos debates na universidade. Sem dúvida, há sim um desafio maior que merece nossa atenção segundo ótica de alguns autores (cf. Pfromm Neto, 1987; Waddington, 1981): Como transmitir conhecimentos e nutrir habilidades e capacidades de forma que o estudante e futuro profissional, possa aprender a aprender ?

\section{NOTAS}

1. A atuação no ensino fundamental e médio deixou de ser o principal interesse dos egressos devido à desvalorização salarial nesse ramo de atuação e a abertura de novas vias de exercício profissional em clubes, academias, hospitais, hotéis, entre outros.

2. O boom de criação laboratórios na EEFEUSP ocorreu entre 1988 e 1990 (Manoel, no prelo; Tani neste número).

\section{REFERÊNCIAS BIBLIOGRÁFICAS}

BOUCHARD, C.; SHEPHERD, R.; STEPHENS, T., eds. Physical activity, fitness and health. Champaign, Human Kinetics, 1993.

BURT, J.J. The role of Kinesiology in elevating modern society. Quest, v.50, p.80-95, 1998.

HENRY, F.M. Physical education: an academic discipline. Journal of Physical Education and Recreation, v.35, p.32-8, 1964.

LAWSON, H.A. Invitation to physical education. Champaign, Human Kinetics, 1984.

MANOEL, E.J. A dịâmica do estudo e da promoção de atividade motora humana: transição de fase na EEFEUSP? Revista Paulista de Educação Fisica, 1999. [no prelo]

Comportamento motor e educação fisica: as duas faces de Jano. Motriz, v.2, p.43-8, 1996a.

Movimento humano: considerações acerca do objeto de estudo da educação física. Boletim da Federação Internacional de Educação Física, v.56, p.33-9, 1986

Preparação profissional: na teoria a prática é outra. Caderno Documentos, n.2, p.23-7, 1996 b.

MANOEL, E.J.; OKUMA, S.S.; De SANTO, D.L. Reflexão e avaliação do curso de bacharelado em educação física: um estudo preliminar da preparação profissional na EEFEUSP. Caderno Documentos, n.3, p.1-55, 1997.

MARIZ DE OLIVEIRA, J.G. Preparação profissional em educação física. In: PASSOS, S.C.E., org. Educação física e esportes na universidade. Brasília, SEED/MEC/UnB, 1988.

MORFORD, W.P. Toward a profession not a craft. Quest, v.18, p.88-93, 1972. 
NEWELL, K.M. Physical education in higher education: chaos out of order. Quest, v.42, p.22742, 1990.

PFROMM NETO, S. Psicologia da aprendizagem e do ensino. São Paulo, EPU/EDUSP, 1987.

RARICK, G.L. The domain of physical education. Quest, v.9, p.49-52, 1967.

TANI, G. Algumas reflexбes sobre o bacharelado em educação física. Caderno Documentos, n.3, p.71-6, 1997.

A atividade de pesquisa na Escola de Educação Física e Esporte da Universidade de São Paulo. Revista Paulista de Educação Física, v.13, p.20-35, 1999. Número especial.

Contribuições da aprendizagem motora à educação física: uma abordagem crítica. Revista Paulista de Educação Física, v.6, p.65-72, 1992.

Cinesiologia, educação física e esporte: ordem emanente do caos na estrutura acadêmica. Motus Corporis, v.3, p.9-50, 1996a.
A dicotomia teoria-prática na preparação profissional em educação física. In: SEMANA DE EDUCAÇÃO FÍSICA, 3., São Paulo, 1995. Anais. São Paulo, Universidade de São Judas Tadeu, 1995.

Pesquisa e pós-graduação em educação física. In: PASSOS, S.C.E., org. Educação fisica e esportes na universidade. Brasilia, SEED/MEC/UnB, 1988. p.379-94.

Vivências práticas no curso de graduação em educação física: necessidade, luxo ou perda de tempo? Caderno Documentos, n.2, p.1-22, 1996b.

. 20 anos de ciências do esporte no Brasil: um transatlântico sem rumo? Revista Brasileira de Ciências do Esporte, p.19-31, 1998. Número especial comemorativo aos 20 anos de Fundação.

WADDINGTON, C.H. Instrumental para o pensamento. São Paulo, EDUSP/Itatiaia, 1981.

WHITING, H.T.A. Editorial. Journal of Human Movement Studies, v.1, p. 14, 1975.

ENDEREÇO: Edison de Jesus Manoel

EEFEUSP

Av. Prof. Mello Moraes, 65

05508-900 - São Paulo - SP - BRASIL 